\title{
Desiccation Resistance of Two Semiterrestrial Isopods, Ligia Exotica and Ligia Taiwanensis (Crustacea) in Taiwan
}

\author{
Min-Li Tsai, ${ }^{1}$ Chang Feng Dai, ${ }^{1}$ and Hon-Cheng Chen ${ }^{2}$ \\ ${ }^{1}$ Institution of Oceanography, National Taiwan University, P.O. Box 23-13 Taipei, \\ Taiwan; and ${ }^{2}$ Department of Zoology, National Taiwan University, Taipei 10764, Taiwan
}

\begin{abstract}
The ability to resist desiccation stress was examined in two semiterrestrial Ligia species, Ligia exotica Roux and L. taiwanensis Lee, in Taiwan, under a certain desiccation condition. L. exotica exhibited the longer survival time, lower weight-specific rates of water loss, and the slightly higher ability of tolerance to water loss, compared to L. taiwanensis. In each species, the animal size displays a positive correlation to the survival time and total ability to resist desiccation, yet this size effects on the weight-specific water loss rate is negative. Neither water content nor maximum tolerance to water loss shows the association with the animal size in both species.

The path ways and magnitudes of the interactions between these traits of desiccation resistance are analyzed and diagrammed using a stepwise regression model. In this model, the body sizes of animal can explain the most part of the variations in the survival time. The body size has a direct effect and an indirect effect, through the effect on water loss rate, on the time that the experimental animals can survival under this desiccated condition.

These results suggest that L. exotica attains larger size than does L. taiwanensis, a lower transpiration rate and, consequently, a greater ability in desiccation resistance. The performances of these interactions in the desiccated resistance are more advantageous for L. exotica to migrate and colonize in variable land habitats within a certain limit, and as a result that L. exotica shows a broader distribution pattern than did L. taiwanensis in Taiwan. сомр віоснем Pнysiol 119A;1:361-367, 1998. (C) 1998 Elsevier Science Inc.
\end{abstract}

KEY WORDS. Desiccation resistance, isopod, Ligia exotica, Ligia taiwanensis, water loss rate, transpiration rate, body size

\section{INTRODUCTION}

Water availability is undoubtedly one of the most important abiotics influencing life (35). Through its effect on physiological performance (5), variation in these factors not only directly accounts for the distribution patterns of species (28), but also indirectly determines distributions via influences on population dynamics $(10,16)$. Consequently, there have been many investigations in the reaction of arthropods to variation in water availability $(1,2,4,9,11,20,25,26,36)$. Many terrestrial crustaceans lose water more rapidly than do other arthropods $(8,19,21,22,24,25,29)$. Under this innate constraint on cuticular permeability, the effect of the ability in desiccation resistance on the distribution pattern is more important in terrestrial or semi-terrestrial crustaceans than in insects.

Address reprint requests to: Min-Li Tsai, Institution of Oceanography, National Taiwan University, P.O. Box 23-13 Taipei, Taiwan. Tel. 886-2-3636040; Fax 886-2-362-6092; E-mail: D5225003@cc.ntu.edu.tw

Received 19 March 1997; accepted 23 July 1997.
Two Ligia species, Ligia exotica and L. taiwanensis, are found in Taiwan to have quite different distribution patterns. L. exotica has a broad distribution. They can be found in the littoral zone of the coasts all around Taiwan (3), and some populations are also found in the inland habitats, e.g., the strand of streams and fish ponds. The distribution of L. taiwanensis, however, is relatively limited. They are only found at the Heng-Cheng Peninsula in southern Taiwan (17), and inhabit the stream strands of tropic rain forest (34).

Although, there exists extensive literature about water balance in terrestrial or semi-terrestrial crustaceans $(7,12$, $13,21,23,24,26,33)$, the inquiries from the viewpoint of individual variations and the interactions between the traits of desiccated resistance, however, are rare. The studies on the variation between individuals and the interactions between physiological traits may provide an insight into the capacities of desiccation resistance and the distribution patterns of these crustaceans. In this study, the ability to resist desiccation stress in two Ligia species, is examined and com- 
pared. These data are needed to understand ecophysiological limitations in the dispersal and habitat colonization of these two Ligia species.

\section{MATERIALS AND METHODS}

Ligia exotica and L. taiwanensis are collected randomly from the littoral zone and strands of mountain brook on the Heng-Chen Peninsula in southern Taiwan, respectively. During transportation, animals were maintained in tanks containing moist substratum from their natural habitats, and covered with plastic plates to maintain high humidity. In the laboratory, animals were acclimated in the tanks with moistened filter paper for two days, allowing them to achieve a standard water balance and clean guts before the experiments. After acclimation, each individual was cleaned with distilled water and put on dry filter paper for $5 \mathrm{~min}$ to remove the exosomatic water. Then, each individual was weighed to $0.01 \mathrm{mg}$.

Each individual from two species was sampled randomly and placed in a dry beaker. Animals in the beakers were directly exposed to air within an enclosed plastic box in which saturated $\mathrm{KCl}$ solution was used to maintain the humidity at a constant level (26). The air temperature and relative humidity in the beaker were then recorded continually using an $\mathrm{HOBO}^{\mathrm{TM}}$ temperature logger and StowAway ${ }^{\mathrm{TM}}$ humidity logger (Onsey Instrument Corporation). The loggers were placed in blank beakers within boxes, as were the experimental animals. The average air temperature and relative humidity were $27.2 \pm 0.4^{\circ} \mathrm{C}$ and $85.2 \pm 2.3 \%$, respectively. The animals were monitored continually until they died. Dead animals that did not respond to being touched with a probe, were then removed and weighed during the experiment, and their survival times were also recorded. The body weights of living animals were recorded at $1 \mathrm{hr}$ intervals. The individuals were then placed in a glass pan, and dried in an oven at $80^{\circ} \mathrm{C}$ for $48 \mathrm{hr}$ and weighed. The maximum tolerance of water loss was estimated by the fatal amount of water loss expressed as the percentage weight loss of fresh body weight. Experimental animals were mostly inactive during the experiment. They snuggled on the bottom in a concern of the beaker, to reduce evaporative rate from the underside, until the final period of experiment. They struggled in the final period before they died. Only the data obtained from the inactive period were used to calculate the rate of water loss, to reduce the error caused by different activities among animals. The individual water loss rate was assessed by average weight loss per hr.

Allometry was used to describe the relationships between body size and the traits of desiccation resistance in the animals (30). Multiple regression and partial correlation were employed to analyze the correlation between these physiological characteristics $(27,37)$. Path analysis is an appropriate method for the study of causes and results among variables which are interrelated but not independent (32). It is applied to diagram a hypothesis of the causality between the physiological characteristics and the ability of desiccation resistance.

\section{RESULTS}

Ligia exotica has lower level water content, slightly greater tolerance to water loss, lower weight-specific water loss rate and longer survival time than L. taiwanensis, under the same desiccation condition (Table 1).

A positive correlation between the survival time and body size is found either in Ligia exotica or L. taiwanensis (Fig. 1). This indicates that the individuals with larger body size can survive longer than do smaller ones, under the same desiccation stress. The amounts of water loss per hr increased with body weight either in Ligia exotica or L. taiwanensis. The relationships between water loss rate and body size followed the allometric equations y $=0.23 \mathrm{~W}^{0.67}$ for L. exotica and $\mathrm{y}=0.52 \mathrm{~W}^{0.68}$ for L. taiwanensis, where $\mathrm{y}$ is the water loss rate ( $\mathrm{mg}$ water per $\mathrm{hr}$ ), and $\mathrm{W}$ is the body dry weight (mg) (Fig. 2). The exponents, however,

TABLE 1. The mean of water content, tolerance of water loss, survival time, and weight-specific water loss rate (at $27.2 \pm$ $0.4^{\circ} \mathrm{C}, 85.2 \pm 2.3 \%$ R.H.) for Ligia exotica $(n=60)$ and Ligia taiwanensis $(n=56)$, and the summary $t$-test results between species

\begin{tabular}{|c|c|c|c|}
\hline Parameters & Species & Mean \pm SD & $\begin{array}{l}\text { Results of } t \text {-test } \\
\text { (between species) }\end{array}$ \\
\hline 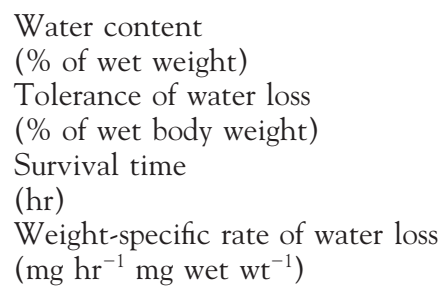 & $\begin{array}{l}\text { L. exotica } \\
\text { L. taiwanensis } \\
\text { L. exotica } \\
\text { L. taiwanensis } \\
\text { L. exotica } \\
\text { L. taiwanensis } \\
\text { L. exotica } \\
\text { L. taiwanensis }\end{array}$ & $\begin{aligned} 77.2 & \pm 1.1 \\
79.7 & \pm 0.6 \\
28.2 & \pm 0.7 \\
27.5 & \pm 0.9 \\
15.5 & \pm 2.6 \\
7.1 & \pm 1.0 \\
0.019 & \pm 0.007 \\
0.039 & \pm 0.010\end{aligned}$ & $\begin{array}{l}\mathrm{s}, \mathrm{p}<0.001 \\
\mathrm{~s}, \mathrm{p}<0.001 \\
\mathrm{~s}, \mathrm{p}<0.001 \\
\mathrm{~s}, \mathrm{p}<0.001\end{array}$ \\
\hline
\end{tabular}

s: Difference between two species is significant. 


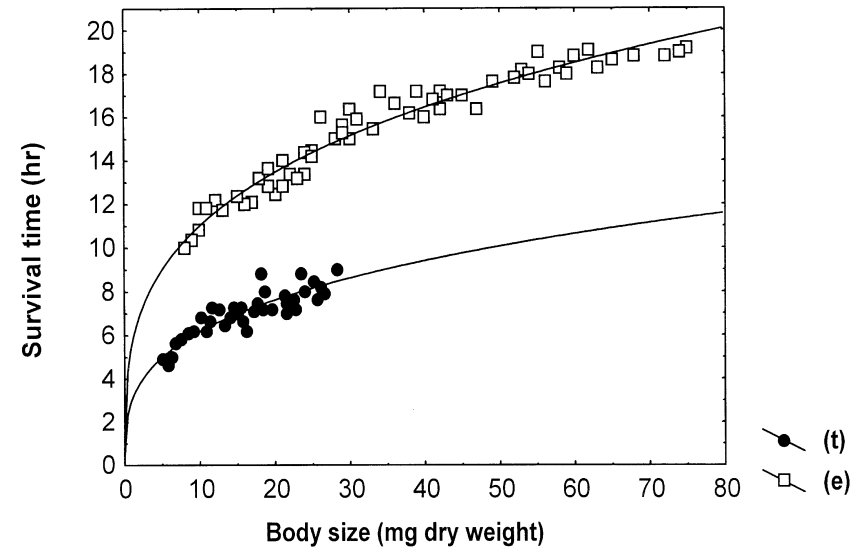

FIG. 1. The relationship between the survival time (hr) and body size (mg dry weight), at $27.2 \pm 0.4^{\circ} \mathrm{C}$ and $85.2 \pm 2.3 \%$ R.H. desiccation stress. (t): Ligia taiwanensis; (e): Ligia exotica.

are similar between the two species (Table 2), and both approximate to 0.67 , an allometric exponent of area (square) vs body weight (cube). Furthermore, the errors of water loss rate between species that might arise from the different activities have been reduced by using the data which are obtained from the animals during the inactive period of the experiment. It seems likely that the different water loss rates of the two species are simply because of the interspecific difference in the cuticular permeabilities.

When the rate of water loss is specified by the fresh weight for each individual, both species show a negative correlation between weight-specific rate of water loss and the body size (Fig. 3). This indicates that larger individuals have lower weight-specific water loss rates than those of smaller ones. The coefficient of allometric equations and the results of statistically significant tests are shown in Table

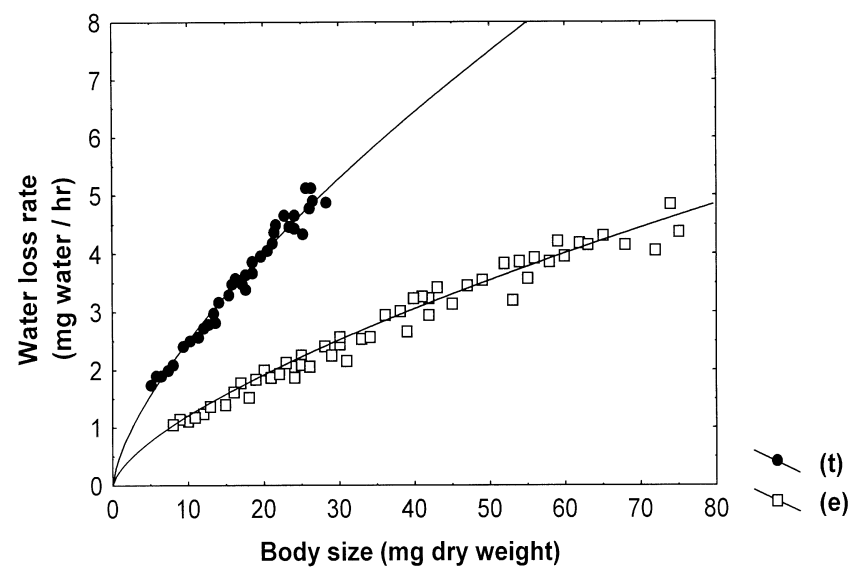

FIG. 2. The relationship between the water loss rate $(\mathrm{mg}$ water/hr) and body size ( $\mathrm{mg}$ dry weight), at $27.2 \pm 0.4^{\circ} \mathrm{C}$ and $85.2 \pm 2.3 \%$ R.H. desiccation stress. ( $t$ ): Ligia taiwanensis; (e): Ligia exotica.
2. In either L. exotica or L. taiwanensis, water content is independent of the body size (Fig. 4). Maximum tolerance to water loss also shows no significant correlation with body size (Fig. 5).

The effect of body size on the traits of desiccation resistance for each species is removed statistically by partial regression. The partial correlation coefficients show a negative correlation $(p<0.001)$ between survival time and the weight-specific water loss rate, in either Ligia exotica or L. taiwanensis. This suggests that individuals with lower weight-specific water loss rate can survive longer under the same desiccation stress. The longer survival time is also associated with the increase of the maximum tolerance of water loss (Table 2). However, there is no significant correlation between maximum tolerance and the weight-specific water loss rate in either species (Table 3).

Path analysis and a stepwise regression model was used to evaluate the effect of any causal variable (body size, maximum tolerance and weight-specific water loss rate) on a criterion variable (survival time): A causal variable which explained a non-significant part of the variations of the criterion variable was excluded. In this case, the weight-specific rate of water loss, a causal variable, is significantly determined by body size (Table 3 and Fig. 3); hence, body size enters the multiple regression model first. Because the maximum tolerance to water loss is not associated with the body size or the weight-specific rate of water loss (Fig. 5 and Table 3), it affects the survival time independently. The results of stepwise regression and the amount of variation that is explained by each causal variable in each step are shown in Table 4. These three causal variables explained almost all the variation of survival time in each species (97.25\% for Ligia exotica and $98.82 \%$ for L. taiwanensis). The size of animals explains a larger part of the variation than does the weight-specific water loss rate alone or the maximum tolerance of water loss (Table 4).

Fig. 6 shows the final diagrams of the path analyses that represent an explicit hypothesis of the causality among the variables. The arrow and the path coefficient indicate the direction and the magnitude of causality, respectively. It seems likely that Ligia exotica and L. taiwanensis have similar interactive patterns among these characteristics of desiccation tolerance. The model of L. exotica, for example, the positive overall effect of body size on survival time $(0.3411$ $+0.8979 \times 0.6707)$ reveals two components, one through an effect on the weight-specific rate of water loss $(0.6707$ $\times 0.8979)$ and one direct (0.3411). The negative effect of the weight-specific water loss rate alone is relatively small $(-(0.6707-0.6707 \times 0.8979))$. The maximum tolerance of water loss also has a small positive effect on survival time (0.1387), independently. The model of L. taiwanensis shows similar results in the directions of interaction. It seems likely that body size is the main factor affecting survival time under this desiccation condition. This result agrees with the 
TABLE 2. Analysis of the relationship between body size and water loss rate, the weight-specific rate of water loss and survival time (time to maximize tolerance of water loss) under the conditions of $27.2 \pm 0.4^{\circ} \mathrm{C}$ and $85.2 \pm 2.3 \% \mathrm{R}$.H. Allometry equation $\mathrm{Y}=\boldsymbol{\beta} \mathrm{W}^{\alpha}$, where $\mathrm{Y}$ is parameter, $\mathrm{W}$ is body dry weight, $\alpha$ and $\beta$ are constants, and $\mathrm{r}$ is the correlation coefficient

\begin{tabular}{|c|c|c|c|c|c|}
\hline Parameter & $\boldsymbol{\alpha}$ & $\boldsymbol{\beta}$ & $\mathbf{r}$ & $\mathbf{F}$ & $\mathbf{p}$ \\
\hline \multicolumn{6}{|l|}{ Water loss rate: } \\
\hline L. exotica & $0.669 * * *$ & $0.225 * * *$ & 0.97 & 2678.99 & $<0.001$ \\
\hline L. taiwanensis & $0.681 * * *$ & $0.522 * * *$ & 0.95 & 2570.01 & $<0.001$ \\
\hline \multicolumn{6}{|c|}{ Weight-specific rate of water loss: } \\
\hline L. exotica & $-0.295 * * *$ & $0.051 * * *$ & -0.92 & 950.68 & $<0.001$ \\
\hline L. taiwanensis & $-0.294 * * *$ & $0.087 * * *$ & -0.85 & 300.16 & $<0.001$ \\
\hline \multicolumn{6}{|l|}{ Survival time: } \\
\hline L. exotica & $0.289 * * *$ & $5.667 * * *$ & 0.89 & 1147.21 & $<0.001$ \\
\hline L. taiwanensis & $0.302 * * *$ & $3.088 * * *$ & 0.79 & 202.45 & \\
\hline
\end{tabular}

*** Significant at the level of $p<0.001$.

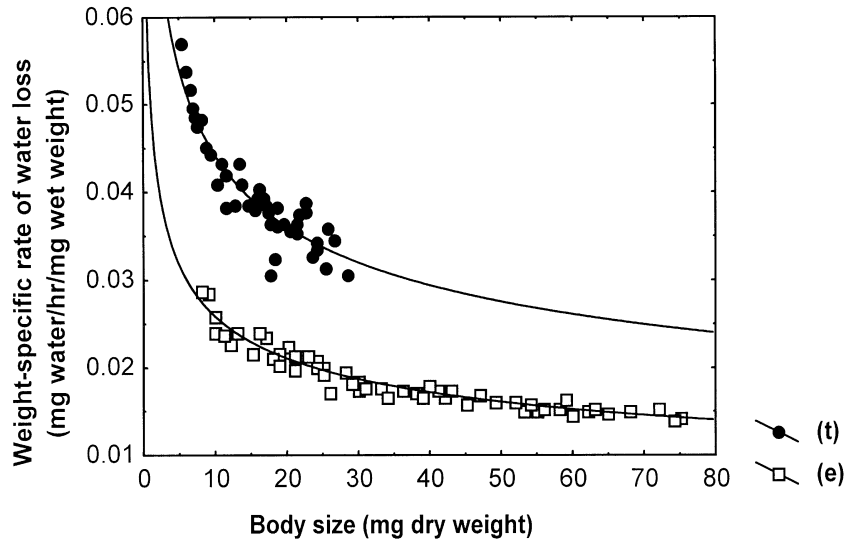

FIG. 3. The relationship between the weight-specific water loss rate $(\mathrm{mg}$ water/hr/mg wet weight) and body size $(\mathrm{mg}$ dry weight), at $27.2 \pm 0.4^{\circ} \mathrm{C}$ and $85.2 \pm 2.3 \%$ R.H. desiccation stress. (t): Ligia taiwanensis; (e): Ligia exotica.

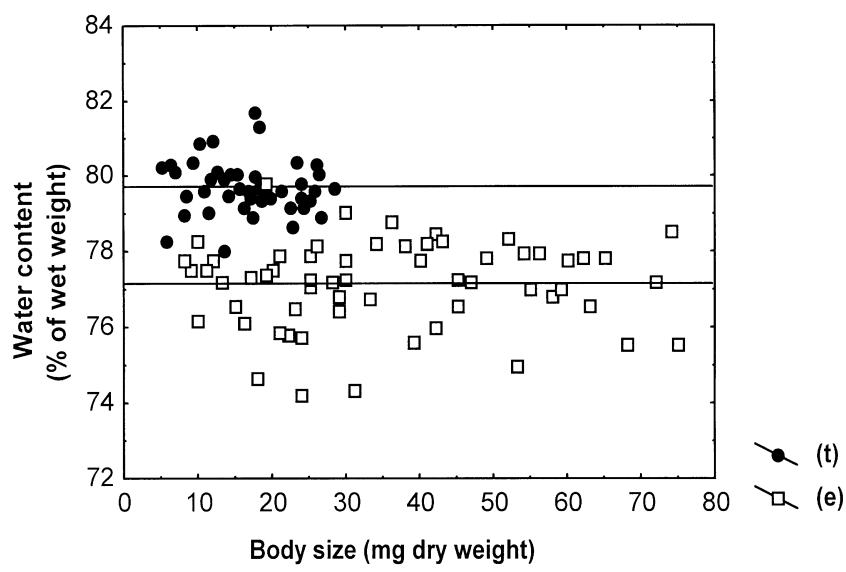

FIG. 4. The relationship between the water content (\% of wet weight) and body size ( $\mathrm{mg}$ dry weight), at $27.2 \pm 0.4^{\circ} \mathrm{C}$ and $85.2 \pm 2.3 \%$ R.H. desiccation stress. $(\mathrm{t})$ : Ligia taiwanensis; (e): Ligia exotica. result of variance analysis of the model (Table 5) wherein the majority of the variation in survival time is explained by body size.

\section{DISCUSSION}

Ligia exotica and L. taiwanensis died, when the average level of water loss was higher than $28.2 \%$ and $27.5 \%$ of body wet weight (36.4\% and $34.6 \%$ of body water), respectively. These figures were higher than comparable data for a number of terrestrial amphipod and decapod crustaceans, e.g., $25 \%$ of body water in the amphipod Orchestia gammarellus, $22 \%$ of body water in the robber crab Birgus latro, 15-18\% of body water in gecarcinid crabs (13), 15-19\% loss of body weight in the amphibious crab Potomon (6), 20\% loss of body weight in Sudanonautes africanus africanus (23) and slightly lower than those data for some terrestrial crabs, e.g., 28-31\% loss of body mass in Holthuisana transversa (12), $33.5 \%$ loss of body mass in Ocypode cordimanus and $32.8 \%$ loss of total mass in Leptograpsus variegatus (33).

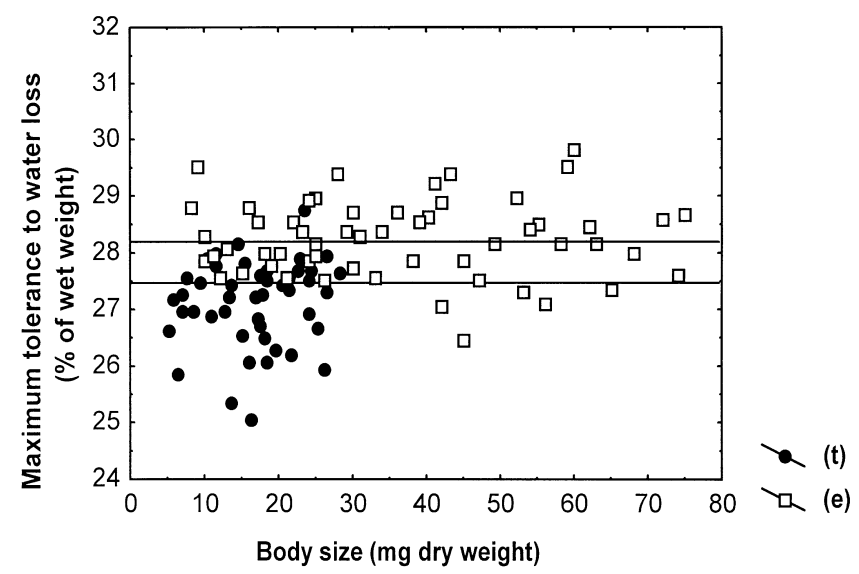

FIG. 5. The relationship between the maximum tolerance to water loss (\% of wet weight) and body size ( $\mathrm{mg}$ dry weight), at $27.2 \pm 0.4^{\circ} \mathrm{C}$ and $85.2 \pm 2.3 \%$ R.H. desiccation stress. $(\mathrm{t})$ : Ligia taiwanensis; (e): Ligia exotica. 
TABLE 3. First order partial correlations (r) between survival time (S.), the weight-specific rate of water loss (W.R.) and the maximum tolerance of water loss (M.T.) when the effect of body weight is removed. Data are for Ligia exotica and Ligia taiwanensis exposed at $27.2 \pm 0.4^{\circ} \mathrm{C}$ and $85.2 \pm 2.3 \%$ R.H. desiccation stress

\begin{tabular}{lrcc}
\hline Species & $\mathbf{r}$ & $\mathbf{t}$ & $\mathbf{p}$ \\
\hline Ligia exotica: & & & \\
S. \& W.R. & -0.8484 & 11.67 & $<.001$ \\
S. \& M.T. & 0.3924 & 3.11 & $<.01$ \\
W.R. \& M.T. & 0.0420 & 0.31 & $\mathrm{~ns}$ \\
Ligia taiwanensis: & & & \\
S. \& W.R. & -0.8944 & 15.09 & $<.001$ \\
S. \& M.T. & 0.2753 & 2.42 & $<.05$ \\
W.R. \& M.T. & 0.0760 & 1.68 & $\mathrm{~ns}$ \\
\hline
\end{tabular}

ns: not significant at the level of $p>0.05$.

Juveniles of the amphipods, Talitrus saltator and Orchestia gammarellus, showed significantly higher weight-specific water loss rates compared with adults $(25,26)$. This was attributable to the much smaller size and concomitant increase in the surface area to volume ratio in juveniles. It is suggested that the high transpiration rates of euterrestrial amphipods can be partly explained by the allometric consideration (26). This study shows similar results. In both Ligia exotica and L. taiwanensis, the larger individuals have lower weight-specific water loss rates than those of smaller individuals. The relationships between the weight-specific rate and body size can also fit the allometric regression equation well. This is one of the ways in which the animals' size affects the survival time in the desiccation stress. A way that the survival time can be extended is through the reduction of the ratio of surface area to volume. The results of path analysis also suggest this. (a) Ligia exotica

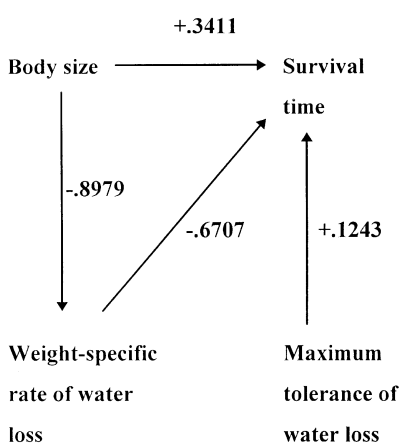

(b) Ligia taiwanensis

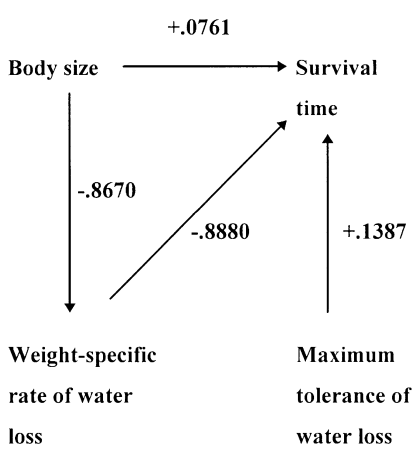

FIG. 6. Path diagrams showing the relationships affecting survival time (time to maximum water loss) for (a) Ligia exotica and (b) Ligia taiwanensis. Path coefficients and arrows indicate the magnitude and direction of each effect, respectively.

The survival times are associated with the weight-specific water loss rate and maximum tolerance to water loss in this study, when the effect of body size is removed. Both weightspecific water loss rate and the maximum tolerance to water loss affected the survival time. These effects on survival time are nothing to do with the size of the animal. The effect of the maximum tolerance on the survival time is, somehow, independent of either body size or the weightspecific water loss rate.

The effect of body size on survival time in this study might reveal two components, one direct and one indirectly through an effect on weight-specific water loss rate. The weight-specific water loss rate alone has a slight negative effect on the survival time. Therefore, the weight-specific water loss rate is closely related to the size of the animal.

However, the interaction patterns among these physio-

TABLE 4. Analysis of the components of the variation in the individual survival time (time to maximum tolerance of water loss) in Ligia exotica and $L$. taiwanensis at $27.2 \pm 0.4^{\circ} \mathrm{C}$ and $85.2 \pm 2.3 \%$ R.H.

\begin{tabular}{|c|c|c|c|c|c|}
\hline Source of variation & df & S.S. & $\mathbf{F}$ & p & $\mathbf{P}(\%)$ \\
\hline \multicolumn{6}{|l|}{ Ligia taiwanensis } \\
\hline Total explained & 3 & 51.7909 & 612.93 & $<0.001$ & 97.22 \\
\hline Body weight & 1 & 38.1134 & 135.92 & $<0.001$ & 71.57 \\
\hline Weight-specific water loss rate & 1 & 10.8784 & 135.98 & $<0.001$ & 20.43 \\
\hline Maximum tolerance of water loss & 1 & 2.7784 & 92.60 & $<0.001$ & 5.22 \\
\hline Unexplained & 52 & 1.4646 & & & \\
\hline Total & 55 & 127.8234 & & & \\
\hline \multicolumn{6}{|l|}{ Ligia exotica } \\
\hline Total explained & 3 & 379.8712 & 1655.94 & $<0.001$ & 98.87 \\
\hline Body weight & 1 & 341.8681 & 468.92 & $<0.001$ & 88.99 \\
\hline Weight-specific water loss rate & 1 & 33.8231 & 225.49 & $<0.001$ & 8.80 \\
\hline Maximum tolerance of water loss & 1 & 4.1800 & 54.64 & $<0.001$ & 1.08 \\
\hline Unexplained & 56 & 4.2821 & & & \\
\hline Total & 59 & 384.1533 & & & \\
\hline
\end{tabular}

$\mathrm{P}(\%)$ : Percentage of total variation which is explained by the variable. 
logical traits for Ligia exotica and L. taiwanensis are similar. Body size explains the majority of the variation in survival time under this desiccation condition.

The physiological traits of desiccation resistance, such as survival time, maximum tolerance and the water loss rate, might limit the ability of animals to colonize various environments $(4,22)$, especially when they invaded to various land habitats. Although the loss of body water in land arthropods might occur in various mechanical ways, such as evaporation from body surface, respiration and excretion, it was suggested that most of the water is lost through integument in terrestrial crustaceans $(14,15)$. Compared with those terrestrial insects in which transcuticular water loss has been found to be only a small part of the total water loss because of their lower cuticular permeability $(8,18,38)$, the integument of land crustaceans seems to lack well proofs to resist water loss.

Under the consideration of the constraint of integument permeability, the body size which related to the loss rate of body water, therefore, becomes more important for terrestrial crustaceans in their ability to colonize various land habitats. It is suggested that larger body size for these terrestrial crustaceans may be advantageous to a mobile species within certain limits (31). Applying this possible implication of, and constraint on, body size to the semiterrestrial Ligia exotica and L. taiwanensis, it is evident that L. exotica attains larger size than does L. taiwanensis, has lower transpiration rate and, hence, has greater ability in the desiccation resistance. Regardless of the interspecific difference in the cuticular permeability, all of these interrelated factors might be advantageous to L. exotica in migration to and colonization of various land habitats within certain limits. Indeed, L. exotica shows a broader distribution pattern rather than that of L. taiwanensis in Taiwan.

\section{References}

1. Arlian, L.G.; Veselica, M.M. Water balance in insects and mites. Comp. Biochem. Physiol. 64A:191-200;1979.

2. Beament, J.W.L. The water relations of insect cuticule. Biol. Rev. 36:281-320;1961.

3. Chen, G.X. The descriptions of two sea-slaters from China. Chine. J. Zool. 22:8-11;1987.

4. Chown, S.L. Desiccation resistance in six sub-Antarctic weevils (Coleptera: Curculionidae): Humidity as an abiotic factor influencing assemblage structure. Func. Ecol. 7:318-325; 1993.

5. Cossins, A.R.; Bowler, K. Temperature Biology of Animals. London: Chapman and Hall; 1987.

6. Dandy, J.W.T.; Ewer, D.W. The water economy of three species of the amphibious crab, Potomon. Trans. Roy. Soc. South. Afri. 36:137-162;1961.

7. Edney, E.B. The evaporation of water from woodlice and the millipede Glomeris. J. Exp. Biol. 28:91-115;1951.

8. Edney, E.B. Woodlice and the land habitat. Biol. Rev. 29: 185-219;1954.

9. Edney, E.B. Zoophysiology and Ecology, Vol. 9. Water Balance in Land Arthropods. Berlin and New York: SpringerVerlag; 1977.
10. Enright, J.T. Climate and population regulation: The biogeographer's dilemma. Oecologia 24:295-310;1976.

11. Gehrken, U.; Somme, L. Tolerance of desiccation in beetles from the high Atlas Mountains. Comp. Biochem. Physiol. 190A:913-920;1994.

12. Greenaway, P.; MacMillen, R.E. Salt and water balance in the terrestrial phase of the inland crab Holthuisana (Austrothelphusa) transversa Martent (Parathelphusoidea: Sundathelphusidae). Physiol Zool. 51:217-229;1978.

13. Harris, R.R.; Kormanik, G.A. Salt and water balance and antennal gland function in three Pacific species of terrestrial crab (Gecarcoidea lalandii, Cardisoma canifex, Birgus latro). II. The effects of desiccation. J. Exp. Zool. 218:107-116;1981.

14. Herreid, C.F. Water loss of crabs from different habitats. Comp. Biochem. Physiol. 28:829-839;1969a.

15. Herreid, C.F. Integument permeability of crabs and adaptation to land. Comp. Biochem. Physiol. 29:423-429;1969b.

16. Kingsolver, J. Weather and the population dynamics of insect: Integrating physiological and population ecology. Physiol. Zool. 62:314-334;1989.

17. Lee, J.D. A new mountain slater, Ligia taiwanensis (Isopoda, Ligiidae) from Taiwan. Crustaceana 66:110-115;1994.

18. Lighton, J.R.B.; Garrigan, D.A.; Duncan, F.D.; Johnson, R.A. Spiracular control of respiratory water loss in female alates of the harvester ant Prgonomyrmex rugosus. J. Exp. Biol. 179: 233-244;1993.

19. Lillywhite, H.B.; Maderson, P.F.A. The structure and permeability of integument. Am. Zool. 28:945-962;1988.

20. Lindqvist, O.V. Components of water loss in terrestrial isopods. Physiol. Zool. 45:316-324;1972.

21. Little, C. The Colonization of Land: Origins and Adaptations of Terrestrial Animals. New York: Cambridge University Press; 1983.

22. Little, C. The Terrestrial Invasion: An Ecophysiological Approach to the Origins of Land Animals. New York: Cambridge University Press; 1990.

23. Lutz, P.L. Salt and water balance in the West African freshwater/land crab Sudanonautes africanus africanus and the effects of desiccation. Comp. Biochem. Physiol. 30:469-480; 1969.

24. Moore, P.G.; Francis, C.H. On the water relations and osmoregulation of the beach-hopper Orchestia gammarellus (Pallas) (Crustacea: Amphipoda). J. Exp. Mar. Biol. Ecol. 94:131-150; 1985.

25. Moore, P.G.; Francis, C.H. Environmental tolerances of beach-hopper Orchestia gammarellus (Pallas) (Crustacea: Amphipoda). Mar. Environ. Res. 19:115-129;1986.

26. Morritt, D. Evaporative water loss under desiccation stress in semiterrestrial and terrestrial amphipods (Crustacea: Amphipoda: Talitridae). J. Exp. Biol. Ecol. 111:145-157;1987.

27. Neter, J.; Wasserman, W.; Kutner, M.H. Applied Linear Statistical Models, 3rd Edition. Tokyo: Tappan Co. Ltd.; 1990.

28. Pianka, E.R. Evolutionary Ecology, 3rd Edition. New York: Harper \& Row; 1983.

29. Power, L.W.; Bliss, D.E. Terrestrial adaptation. In: Vernberg, F.J.; Vernberg, W.B. (eds). The Biology of Crustacea, Vol. 8. New York: London Academic Press; 1983:271-334.

30. Reiss, M.J. The Allometry of Growth and Reproduction. New York: Cambridge University Press; 1989.

31. Richardson, A.M.M.; Devitt, D.M. The distribution of four species of terrestrial amphipods (Crustacea, Amphipoda: Talitridae) on Mount Wellington, Tasmania. Aust. Zool. 21:143$156 ; 1984$

32. Sokal, R.R.; Rohlf, F.J. Biometry, 2nd Edition. San Francisco: Freeman; 1981.

33. Taylor, H.H.; Greenaway, P. The partitioning of water and 
solutes during evaporative water loss in three terrestrial crabs. Physiol. Zool. 67:539-565;1994.

34. Tsai, M.L.; Dai, C.F.; Chen, C.C. The responses to osmotic stress of two semiterrestrial isopods, Ligia exotica and L. taiwanensis (Crustacea) from southern Taiwan. Comp. Biochem. Physiol. 118(1):141-146;1997.

35. Walter, H. Vegetation of the earth and ecological systems of the geobiosphere. Berlin: Springer-Verlag; 1979.
36. Wharton, G.H. Water balance of insect. In: Kerkut, G.A.; Gilbert, L.I. (eds). Comparative Insect Biochemistry, Physiology and Pharmacology, Vol. 4. Oxford: Pergamon Press; 1985: 565-601.

37. Zar, J.H. Biostatistical Analysis. 2nd Ed. Englewood Cliffs: Prentice Hall; 1984.

38. Zachariassen, K.E. Routes of transpiratory water loss in a dry habitat tenebrionid beetle. J. Exp. Biol. 157:425-437;1991. 